\title{
Understanding Race/Ethnicity Differences in Offending Across the Life Course: Gaps and Opportunities
}

\author{
Alex R. Piquero \\ Received: 12 August 2014 / Accepted: 2 February 2015 / \\ Published online: 4 March 2015 \\ (C) Springer International Publishing AG 2015
}

\begin{abstract}
Race and ethnicity are two of the strongest yet least understood and underexplored correlates of offending. This essay highlights the need for theoretical and empirical research on longitudinal patterns of offending across race and ethnicity so as to expand the traditional focus of developmental and life course criminology. It also uses data from a sample of serious youthful offenders transitioning from mid-adolescence into early adulthood to examine differential patterns of offending across race and ethnic groups. An ambitious agenda for future research concludes the essay.
\end{abstract}

Keywords Race Ethnicity $\cdot$ Longitudinal $\cdot$ Offending $\cdot$ Life-course

\section{Introduction}

It is indeed a great honor to be part of the first set of papers to appear in what I believe will be a key journal not only for developmental/life-course criminology (DLC) researchers but also the field of criminology more generally. As I sat down to think about what I would write about, I felt a bit overwhelmed as there are many theoretical, empirical, and policy-relevant issues in DLC that are in need of attention and commentary. But slowly, things came into focus.

Where did DLC come from? That is actually a relatively easy answer, as Quetelet documented back in the mid-1800s that age is a very strong propensity for crime. Not surprisingly, age as a correlate of crime has been a mainstay, albeit a very controversial one, in the discipline of criminology $[9,23,39,51]$. Without question, age is a key cog in DLC. But there are several others, such as gender, that have been a focus among DLC scholars $[2,19]$. This essay tackles one issue that I strongly believe has been most underrepresented in the study of DLC, perhaps not because of lack of interest, but instead likely because of the lack of data sources as well as a general unease to engage

\footnotetext{
A. R. Piquero $(\bowtie)$

University of Texas at Dallas, Richardson, TX, USA

e-mail: apiquero@utdallas.edu
} 
in very difficult discussions concerning it: the study of race/ethnicity in DLC. It is also an essential issue that deserves theoretical and empirical attention.

Herein, I consider some basic descriptive facts regarding the association between race/ethnicity and longitudinal patterns of offending, summarizing what little information there is. Then, I turn toward some brief remarks regarding the relative color-blindness of most criminological theories - and with just a few exceptions - most DLC theories. I then present some findings using data from the Pathways to Desistance study, a large longitudinal investigation of a sample of serious youthful offenders in Philadelphia and Phoenix that allows me to consider race/ethnic differences in both self-reported and official records. Lastly, I end with a more expanded section detailing an agenda for research that considers race/ethnicity and crime over the life course. In so doing, I also call upon DLC researchers to think about race/ethnicity in a culturally, nationally, and internationally attuned context. One key theme that emerges from my work, with apologies to Michael Jackson, is that it is not just black or white, but all shades in between, including in particular the increasingly important role of immigration and crime.

\section{Basic Description}

There are a handful of consistent - and controversial - correlates of crime, with most criminological attention focused on the relationship between age and crime $[9,23,39$, 51]. Equally consistent - and no less controversial - is the relationship between race/ethnicity and crime $[22,33,36,55]$. Consider a brief review of the facts.

In official (primarily arrest) records, research has historically revealed that minorities (primarily Blacks because of the lack of other race/ethnicity data) are overrepresented in crime, especially serious crimes such as violence. More recently, this conclusion has started to be questioned, as researchers have started to better study and document the potential Hispanic effect [49]. Analyses of self-reported offending data reveal a much more similar set of estimates regarding offending across race, again primarily in BlackWhite comparisons, but increasingly also in comparisons with other ethnic groups [17, 54]. Analyses of victimization data between 2003 and 2012 reveal that Blacks and American-Indian/Alaska Natives are disproportionately victims of violent crime - and especially serious violent crime (the latter which reveals very small participation rates among Whites) [56]. The one crime type that has tended to reveal the starkest differences across race/ethnicity is homicide. An analysis of homicide victimization rates between 1980 and 2008 showed that the Black victimization rate was consistently higher than the White rate, although the gap has been decreasing since the mid-1990s. As well, the homicide offending rates during this time period showed a virtually similar pattern, with Blacks overrepresented in homicide offending, with a decreasing (but still sizable) gap at the end of 2008 [14]. And perhaps the most notable race/ethnic differences with respect to crime data emerge from correctional data, where the incarceration rate of Blacks - and especially Black males - is much higher than that of Whites [52,53], although this association is highly variable at the state level and may be influenced by differential arrest rates (see e.g., [7, 8, 15, 48]). As well, recent research that has examined correctional data for Hispanics shows the group's sizable presence, which at the federal level has been largely centered on immigration offenses [25]. 
Aside from these overall trends, analyses of race/ethnic differences in criminal offending using longitudinal data sources has tended to be more the exception than the rule. This is due, in part, to data limitations regarding long-term data on both official records and selfreports of offending across race and especially ethnicity [42, 43], as most research has tended to focus solely on comparisons between Blacks and Whites [38]. Early research by criminal career researchers, focusing on Black-White comparisons, revealed that race differences in offending were driven primarily by race differences in participation, or the proportion of the population whom offended, as opposed to differences in the frequency of offending among those who have offended, the latter which tends to show few race differences [40]. Some recent and important research using data from the National Longitudinal Survey of Youth 1997 cohort continued to show race/ethnic differences in the prevalence of arrest, such that by age $23,49 \%$ of Black males, $44 \%$ of Hispanic males, and $38 \%$ of White males had been arrested $[11,12]$.

\section{Explanations Regarding Race/Ethnic Differences}

Above, I provided a very broad overview of the main facts regarding race and ethnic differences in offending. But perhaps the more interesting question concerns the theoretical reasons as to why these differences emerge. Before delving into the various theoretical frameworks, I provide an initial sketch, at a much larger level, regarding the two main processes that may explain racial/ethnic overrepresentation in offending and correctional statistics, differential enforcement and differential selection. Although not discussed here, a third process includes a hybrid of both differential enforcement and differential offending, arguing that instead of apportioning a certain amount of explanatory power to each of the two explanations, a combined framework would help to clarify how both differential offending and differential participation intermix at various decision points to influence minority overrepresentation in both offending and correctional data (see [38]).

The first of these two explanations, differential enforcement, focuses attention on how minorities are treated at each stage of the criminal justice system process, beginning with the decision to patrol certain areas and subsequently stop persons of color. It is common knowledge that police tend to differentially patrol areas within a jurisdiction that have higher street — especially violent — crime rates. Although not always the case, these same areas are also both economically disadvantaged and disproportionately populated by racial and ethnic minorities. Thus, differential police patrol will have some influence on minorities coming into contact with the police. After the police decision to stop and then arrest, the remaining stages of the criminal justice process "kicks-in," with research tending to show that racial and ethnic overrepresentation increases as persons go through the entire juvenile and criminal justice process such that by the time the incarceration decision (yes/no as well as length) is reached, differences are at their maximum ([37]:4; [6]:445), yet systematic or overt bias among criminal justice agents has neither been adequately nor empirically demonstrated ([45]:362). As well, the evidence is mixed with respect to racial differences or bias throughout the entire criminal justice process as opposed to some stages more than other stages [59].

The second explanation, differential offending, avoids focusing on the decisions of the criminal justice system in lieu of the overrepresentation of minorities in offending behavior. The crux of this explanation is that minorities tend to have more and higher 
levels of the key risk factors associated with offending, such as residence in disadvantaged neighborhoods, compromised familial situations, exposure to violence, limited education attainment, employment difficulties, and so forth. Many of the classic criminological theories, however, are virtually silent on race/ethnicity such that they do not make explicit predictions regarding offending patterns across race/ethnicity. It would be inferred simply that minorities have "more" of the risk factor or cause in question, i.e., weaker self-control, more associations with delinquent peers, exposure to more and different kinds of stress, and so forth. Two theoretical frameworks, however, make race/ethnicity prominent in understanding criminal activity.

The first of these is Anderson's [1] street code thesis. Briefly, Anderson was particularly interested in understanding the variation in serious violence within large urban cities. His search led him to consider how impoverished neighborhoods and limited educational and employment opportunities in those neighborhoods served to compromise the outlook that many adolescents and adults had with respect to being part of mainstream society. This sense of alienation helped to create fertile conditions for the development of a type of social order, the street code, that helped to govern the behavior of (predominantly Black) males in inner-city neighborhoods. In short, adoption of the street code centers mainly around respect from peers on the street and emphasizes attitudes reminiscent of Walter Miller's [28] focal concerns, including toughness, street smarts, violence, and retribution. On the street, one's reputation is made by subscribing to - and acting upon - this street code. Although there are many more aspects regarding Anderson's street code thesis, they are discussed in detail elsewhere as well as in the empirical tests that have been generally favorable to the central tenants of his theory (see [50]).

The second framework that considers race/ethnic differences, and the only to do so in a DLC framework, is Moffitt's [29] developmental taxonomy, which was created to isolate and describe the heterogeneity among offenders and their offending patterns that combined to form the aggregate relationship between age and crime. Moffitt argues that instead of one overall curve explaining the criminal offending of the entire offender population, the relationship between age and crime is best conceptualized as the product of the offending styles of two distinct groups of offenders, each of whom offends for different reasons and each of whom has a different shape, pattern, and level of offending over the life course.

The first group of offenders, adolescence-limited (AL), represents the largest group of offenders who offend primarily during the adolescent period. In large part, AL's offend for two interrelated reasons. The first is the unique situation that $\mathrm{AL}$ offenders find themselves in during adolescence, biologically like adults but socially/legally not allowed to partake in adult-like activities. This "maturity gap" acts as a source of strain and stress, and when coupled with similarly situated peers who are also experiencing this gap, AL offenders engage in acts that symbolize adult social status and/or acts that provide them with the resources to enjoy some of the pleasures of adulthood, including alcohol and drug use, promiscuous sexual activity, theft, and vandalism - but not violence. As well, for a small handful of AL offenders who experience some sort of adverse outcome due to their offending, such as a criminal record, drug addiction, or unwanted pregnancy, they may become ensnared into a prolonged criminal lifestyle and offending pattern. Otherwise, the majority of AL offenders move away from delinquency as adulthood approaches fostered by an interest in attaining academic and professional credentials which provide ample legal opportunities to engage in adult behaviors. 
Unlike the short-term AL offenders, Moffitt's second group, life-course-persistent, evince an entirely different pattern of offending throughout the life course and does so for dramatically different reasons. For this group, the genesis of offending is located during pregnancy and in the first few months and years of life. Specifically, the onset and progression of neuropsychological deficits, when met with disadvantaged familial and socioeconomic environments that are ill-equipped to help persons overcome those deficits, leads to problems in school as well as interpersonal relationships. As these youth repeatedly experience failure across various life domains, doors to prosocial activities and institutions start to close and few remain open. The offending repertoire of life-course-persistent (LCP) offenders is varied and has no bounds. These offenders begin their involvement in antisocial behavior early in the life course and progress to more age-appropriate behaviors and offenses across the life span. As they suffered from injurious childhoods, which led to their neuropsychological problems being left unaddressed, stability (and not change) is the customary pattern of offending and misbehavior for LCP offenders. Only a select few LCP offenders are able to recover from their early deficits and problem behavior, but very little is known about them [31].

Importantly, Moffitt [30] was cognizant of the important gender and race differences with respect to life-course patterns of offending and briefly sketched out a set of expectations regarding why there are important race differences in offending. At that time, she had not considered differences across ethnicity. In particular, she ([30]:39, emphasis in original) noted:

In the United States, the crime rate for black Americans is higher than the crime rate for whites. The race differences may be accounted for by a relatively higher prevalence of both Life-Course-Persistent and Adolescence-Limited subtypes among contemporary African-Americans. Life-Course Persistent anti-socials might be anticipated at elevated rates among black Americans because the putative root causes of this type are elevated by institutionalized prejudice and by poverty. Among poor black families, prenatal care is less available, infant nutrition is poorer, and the incidence of exposure to toxic and infectious agents is greater, placing infants at risk for the nervous system problems that research has shown to interfere with prosocial child development. To the extent that family bonds have been loosened and poor black parents are under stress,... and to the extent that poor black children attend disadvantaged schools..., for poor black children the snowball of cumulative continuity may begin rolling earlier, and it may roll faster downhill.

In addition, the implications of Adolescence-Limited crime are probably more serious for black youths than for white youths. If racially-segregated communities provide greater access to Life-Course-Persistent role models, then circumstances are ripe there for youths with no prior behavior problems to mimic delinquent ways. Moreover, blacks spend more years in the maturity gap, on average, than whites because ascendancy to valued adult roles and privileges comes later, if at all. Legitimate work is closed to many young black men; they do not shift from having "little to lose" to having "a stake in conformity" overnight by leaving school and entering the world of work (Gibbs, 1988). More time spent in the maturity gap should increase the probability of incurring a "snare" that delays 
desistance: unplanned parenthood, an addiction, a felony record, an injury. Indeed, the biological maturity gap is perhaps best seen as an instigator of adolescent-onset delinquent for black youths, with an economic maturity gap as the agent of maintenance.

Thus, Moffitt anticipates that Blacks will be overrepresented in both offending styles. To date, however, there have been only a handful of empirical investigations of these hypotheses, in large part because of the data requirements needed (see [3, 21, 41]). These studies, however, do offer some preliminary support for several of Moffitt's race-based hypotheses.

In short, the lack of theory and data continue to impede the accumulation of empirical knowledge regarding race and ethnic differences in offending, but this is slowly changing - especially with respect to empirical work in the corrections area as well as the FBI's collection of data on ethnicity for its annual Uniform Crime Report. In the next section of this article, I offer an empirical example of the kind of analysis that can and should be undertaken with respect to investigating race/ethnic differences in life-course patterns of offending using a unique set of data collected on a sample of serious adolescent offenders who are transitioning between adolescence and early adulthood.

\section{Race/Ethnic Differences in Offending in the Pathways to Desistance Study}

Participants in the Pathways to Desistance Study are youth who were found guilty of a serious offense (almost entirely felony offenses) in the juvenile or adult court systems of Maricopa County, AZ or Philadelphia County, PA. These youth were ages 1417 years at baseline. A total of 1354 adolescents are enrolled in the study, representing about one in three adolescents adjudicated on the enumerated charges in each locale during the recruitment period (November 2000 through January 2003). The full sample is comprised of predominantly minority (41.4\% African-American, $33.5 \%$ Hispanic) males $(86.4 \%)$. Information regarding the rationale and overall design of the study can be found in Mulvey et al. [34], while details regarding recruitment, a description of the full sample, and the study methodology may be found in Schubert et al. [47].

In this paper, I use the official record database for the sample throughout the 84month follow-up period. ${ }^{1}$ These data, based on petitions found in juvenile records in each jurisdiction prior to age 18 and arrests appearing in FBI records thereafter, were assigned to a recall period based on the date of the petition/arrest as mapped onto the dates covered within a recall period (see [42, 43]). Through the 84-month period, Whites accumulated 925 total arrests, Blacks accumulated 1768 arrests, Hispanics accumulated 1513 arrests, and other race/ethnicity accumulated 201 arrests. When these raw figures are considered in light of the number of youth in each race/ethnic category, the overall rate of arrest for 7 years (total arrests $/ n$ ) is very similar: Whites=

\footnotetext{
${ }^{1}$ In the interest of space, I limit this example to the use of official records. Data obtained from self-reports should also be examined in this manner. As well, the combination of official records and self-report offending data offers important opportunities to examine issues related to the validity of crime data [42, 43] and specialization-in-offending $[11,12]$, both of which have been carried out with the Pathways data.
} 
3.375, Blacks $=3.151$, Hispanics $=3.332$, and others $=3.092$. Because the size of the other race/ethnicity group is very small and because this group contains several other groups, the remainder of the analysis excludes them.

To present the arrest-based information in ways that are both illustrative and potentially generating of hypotheses for the observed trends, I graph the total arrest frequency at each follow-up for Whites, Blacks, and Hispanics (Fig. 1) as well as the rate of arrest over time across the same three groups (Fig. 2). ${ }^{2}$ Consider the results for the total arrest frequency. At the first follow-up period (baseline through 6 months), the total arrest frequency across groups is very similar, yet at no time period do Whites incur more arrests than either Blacks or Hispanics. Even more striking, as the study progresses over time, the gap between Whites and both Blacks and Hispanics in total arrest frequency widens tremendously, and in some cases, the total number of arrests incurred by Blacks is double (or more) than that incurred among Whites. Thus, when considered in this manner, Whites offend much less over time, while Blacks and Hispanics increase and remain quite stable over time.

Turning to the rate of arrest over time (Fig. 2), the glaring and sizable differences that emerged above with the frequency data are lessened significantly and in several cases virtually disappear. Here, it can be seen that through about 36 months, the rate of arrest tends to be higher for Whites than that for either Blacks or Hispanics whose rates resemble each other closely. After that point, the rate of arrests across groups tends to be quite similar, though at times favoring non-Whites, but these differences are not stellar. Finally, when considering the trends over time, the White rate tends to decline over time, while stability (and even some increase) is observed in the arrest rate for both Blacks and Hispanics. Thus, persistence seems to be more common among Blacks and Hispanics as they transition out of adolescence and into early adulthood (see also [16]). Clearly, this descriptive pattern of findings deserves scrutiny, and consideration of several criminological frameworks - including Moffitt's [30] economic maturity gap hypothesis about persistence among blacks - is in order.

\section{Agenda}

My intent in writing an essay on the topic of race/ethnicity and crime for the inaugural issue of Journal of Developmental and Life Course Criminology was motivated in large part by what I see as one of the most important gaps in DLC generally and, quite frankly, in criminology in particular. Of all of the correlates or facts of crime, the one that in my view has been the least studied is that centered on race/ethnic differences in antisocial and criminal behavior over the life course. What then should DLC scholars do to help begin to fill this gap? Below, I sketch out several research opportunities that seek to both provide basic description about the relationship between race/ethnicity and crime but also that may help to spur further work on where the similarities and differences are with respect to the causes and correlates of offending over the life course.

\footnotetext{
${ }^{2}$ For both figures, Whites are denoted with horizontal lines, Blacks with solid fill, and Hispanics with slanted lines.
} 


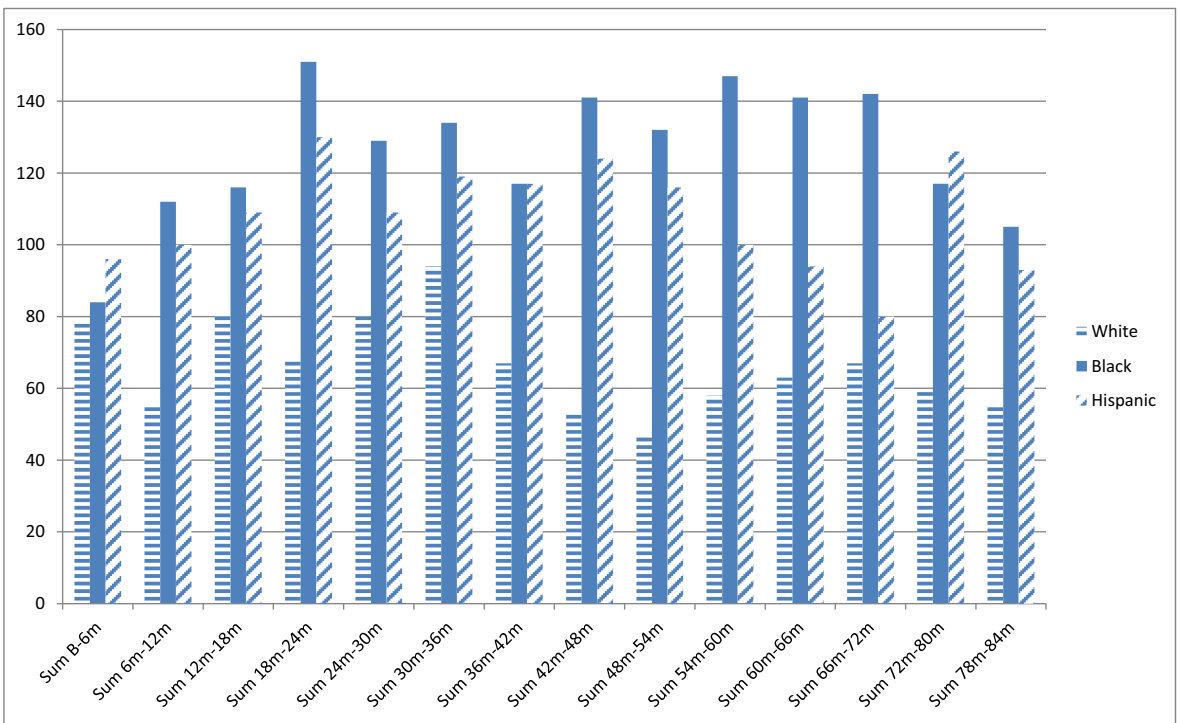

Fig. 1 Pathways total arrests over time, by race/ethnicity

The first and most pressing need concerns the collection of offending data across race and ethnicity. In the USA, at the federal level, data have only been available for White and Black comparisons, and even then arrest rate data among Blacks was not reproduced by age. Only recently has been there a decision to have police agencies collect data on Hispanic offenders and then transmit that data to the FBI. Data on Hispanics has been the most glaring omission in publicly available official data sources, especially at the federal level and for the most part at the state and local levels. There are, however, some jurisdictions and states that do collect and publish offending

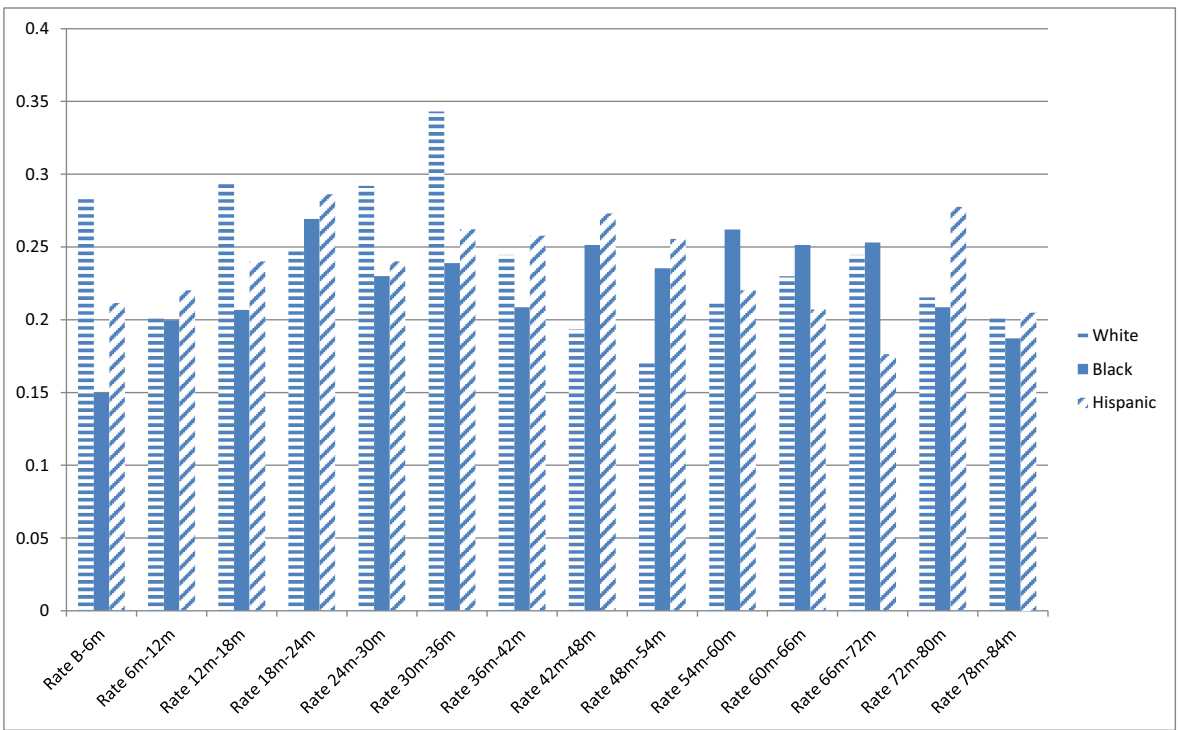

Fig. 2 Pathways rate of arrest over time, by race/ethnicity 
information on Hispanic offenders. In order for a clearer picture to emerge, at least with respect to arrest patterns across race/ethnicity, information should be collected and published on arrests among as many groups as possible as well as doing so by age. It is unfortunate that in early 2015 , one cannot produce an age/crime relationship by crime type, across various race/ethnic categories. The collection of race/ethnicity-specific data should also be made a priority in original data collection efforts regarding self-reported offending and victimization, as well as longitudinal studies that track persons over time. This will enable researchers to better compare race/ethnic differences in offending and victimization across multiple data sources, which remains almost entirely understudied $[42,43]$.

In addition to data collection on offending across major race/ethnic groups, there is an important need to consider offending data on indigenous populations and immigrants broadly speaking (cf. [10, 18]). The oftentimes subjective public and policy discussions and debates on the role that immigration has on crime in the USA in particular is concerning. With some important exceptions at the macro level [27, 35, 58], data limitations has precluded prolonged study of the relationship between immigration and crime - a problem that is even more pronounced at the individual-level of analysis where there is very little information on the offending patterns of immigrant generations and native-born persons to make the sort of comparisons needed (for exceptions, see $[4,5,24,26])$. Until such information is collected, analyzed, and released, the immigration/crime linkage will remain, outside of academia, fraught with prejudice and error.

Aside from data, there is a pressing need to assess the scope conditions of extant criminological theories as well as to rigorously investigate the race-focused street code thesis as well as the race-based hypotheses from Moffitt's taxonomy over the life course (cf. [13, 32]). One emerging fact of crime appears to be the persistence in offending observed among minorities, especially Blacks, that has appeared in at least two different studies, aside from the data reported on in my paper, using both official and self-reported data (see $[16,21])$. Why males and minorities experience this overrepresentation should be a key focus for researchers (see also [46]:33). Aside from testing these accounts, researchers need to seriously pay attention to the measurement properties of psychometric scales across race/ethnicity (e.g., [57]) and should also consider risk and protective factors that may be race-/ethnic-specific [20]. In particular, the roles of assimilation and acculturation among Hispanics and especially Hispanic immigrants in the USA appear relevant for consideration. And outside the USA, the role of immigration in Europe, Asia, and Australia, as well as unique risk and protective factors among indigenous persons in Australia, needs to be carefully documented and better understood. As well, there remains a need to consider the mechanisms by which race/ethnic differences in correctional data emerge the way they do. All aspects of the juvenile and criminal justice system, as well as the school discipline system which has emerged as a potential entrance way into the juvenile justice system especially in the USA, should be scrutinized.

Finally, there is a need for both better thinking about race/ethnicity and offending over the life course as well as consideration of the implications for developmental and life-course theories and researchers that emerge from empirical work on race-specific offending patterns and dimensions. Theoretical modifications and advances are surely to emerge from these new data and resultant findings. As well, some aspects of 
race/ethnic differences in longitudinal offending patterns may be also assessed with alternative methodological orientations, especially qualitative and ethnographic research, which has itself generated important insights into the lives of minorities, their environment, and the crime and violence that may ensue (cf. [1]). For example, contextual differences in neighborhoods and living conditions are evidence in many inner-city minority communities [44]. How do these differences play out with respect to the onset of offending? Do such differences also influence parental structure and socialization? How do these processes play out with respect to potential race/ethnic differences in crime in childhood? adolescence? adulthood? (cf. [41]). The extent to which race-/ethnic-specific theories is, of course, an empirical question and whether the complexity needed with separate theoretical explanations remains to be resolved.

This is an admittedly ambitious research agenda. My goal is that this essay will initiate work on these and related issues. My hope is that when the 25th anniversary issue of the Journal of Developmental and Life Course Criminology is conceived and published that there will have been important strides on the longitudinal relationship between race/ethnicity and crime.

\section{References}

1. Anderson, E. (1999). Code of the street: decency, violence, and the moral life of the inner city. New York: Norton.

2. Baskin, D. R., \& Sommers, I. B. (1998). Casualties of community disorder: women's careers in violent crime. Boulder: Westview Press.

3. Bellair, P., McNulty, T., \& Piquero, A.R. (2014). Verbal ability and persistent offending: a race-specific test of Moffitt's theory. Justice Quarterly, forthcoming.

4. Bersani, B. E. (2014). An examination of first and second generation immigrant offending trajectories. Justice Quarterly, 31, 315-343.

5. Bersani, B., Loughran, T., \& Piquero, A.R. (2014). Comparing patterns and predictors of immigrant offending among a sample of adjudicated youth. Journal of Youth and Adolescence, forthcoming.

6. Bishop, D. M., \& Leiber, M. J. (2012). Racial and ethnic differences in delinquency and justice system responses. In B. C. Feld \& D. M. Bishop (Eds.), The Oxford handbook of juvenile crime and juvenile justice (pp. 445-484). New York: Oxford University Press.

7. Blumstein, A. (1982). On the racial disproportionality of United States' prison populations. Journal of Criminal Law and Criminology, 73, 1259-1281.

8. Blumstein, A. (1993). Racial disproportionality of U.S. prison populations revisited. University of Colorado Law Review, 64, 743-760.

9. Blumstein, A., Cohen, J., Roth, J. A., \& Visher, C. A. (Eds.). (1986). Criminal careers and 'career criminals'. Washington DC: National Academy Press.

10. Brame, R., Mazerolle, P., \& Piquero, A. R. (2010). Criminal career progression in early adulthood in a sample of serious offenders in Australia. Journal of Criminal Justice, 38, 340-348.

11. Brame, R., Bushway, S. D., Paternoster, R., \& Turner, M. G. (2014). Demographic patterns of cumulative arrest prevalence by ages 18 and 23. Crime \& Delinquency, 60, 471-486.

12. Brame, R., Mulvey, E.P., Piquero, A.R., \& Schubert, C.A. (2014). Assessing the nature and mix of offences among serious adolescent offenders. Criminal Behaviour \& Mental Health, forthcoming.

13. Cardwell, S., Piquero, A.R., Jennings, W.G., Copes, H., Schubert, C.A., \& Mulvey, E.P. (2015). Variability in moral disengagement and its relation to offending in a sample of serious youthful offenders. Criminal Justice \& Behavior, forthcoming.

14. Cooper, A., \& Smith, E. L. (2011). Homicide trends in the United States, 1980-2008. Annual rates for 2009 and 2010. Washington, DC: U.S. Department of Justice, Bureau of Justice Statistics.

15. Crutchfield, R. D., Bridges, G. S., \& Pitchford, S. R. (1994). Analytical and aggregation biases in analyses of imprisonment: reconciling discrepancies in studies of racial disparity. Journal of Research in Crime \& Delinquency, 31, 166-182. 
16. Elliott, D. S. (1994). Serious violent offenders: onset, developmental course, and termination. Criminology, 32, 1-21.

17. Farrington, D. P., Loeber, R., Stouthamer-Loeber, M., Van Jammen, W., \& Schmidt, L. (1996). Selfreported delinquency and a combined delinquency seriousness scale based on boys, mothers, and teachers: concurrent and predictive validity for African-Americans and Caucasians. Criminology, 34, 493-517.

18. Fitzgerald, R., Mazerolle, P., Piquero, A. R., \& Ansara, D. L. (2012). Exploring sex differences among sentenced juvenile offenders in Australia. Justice Quarterly, 29, 420-447.

19. Giordano, P. C., Cernkovich, S. A., \& Rudolph, J. L. (2002). Gender, crime, and desistance: toward a theory of cognitive transformation. American Journal of Sociology, 107, 990-1064.

20. Hawkins, D. F., Laub, J. H., \& Lauritsen, J. L. (1998). Race, ethnicity, and serious juvenile offending. In R. Loeber \& D. P. Farrington (Eds.), Serious \& violent juvenile offenders: risk factors and successful interventions (pp. 30-46). Newbury Park: Sage.

21. Haynie, D. L., Weiss, H. E., \& Piquero, A. R. (2008). Race, the economic maturity gap, and criminal offending in young adulthood. Justice Quarterly, 25, 595-622.

22. Hindelang, M. J. (1978). Race and involvement in common law personal crime. American Sociological Review, 43, 93-109.

23. Hirschi, T., \& Gottfredson, M. R. (1983). Age and the explanation of crime. American Journal of Sociology, 89, 552-584.

24. Jennings, W. G., Zgoba, K. M., Piquero, A. R., \& Reingle, J. M. (2013). Offending trajectories among native-born and foreign-born Hispanics to late middle age. Sociological Inquiry, 83, 622-647.

25. Lopez, M. H., \& Light, M. T. (2009). A rising share: Hispanics and federal crime. Washington, DC: Pew Hispanic Center.

26. Maldonado-Molina, M. M., Piquero, A. R., Jennings, W. G., Bird, H., \& Canino, G. (2009). Trajectories of delinquency among Puerto Rican children and adolescents at two sites. Journal of Research in Crime and Delinquency, 46, 144-181.

27. Martinez, R., Jr., Stowell, J. I., \& Lee, M. T. (2010). Immigration and crime in an era of transformation: a longitudinal analysis of homicides in San Diego neighborhoods, 1980-2000. Criminology, 48, 797-829.

28. Miller, W. (1958). Lower-class culture as a generating milieu of gang delinquency. Journal of Social Issues, 14, 5-19.

29. Moffitt, T. E. (1993). Adolescence-limited and life-course-persistent antisocial behavior: a developmental taxonomy. Psychological Review, 100, 674-701.

30. Moffitt, T. E. (1994). Natural histories of delinquency. In E. Weitekamp \& H. J. Kerner (Eds.), Crossnational longitudinal research on human development and criminal behavior (pp. 3-61). Dordrecht: Kluwer Academic Press.

31. Moffitt, T. E., Caspi, A., Harrington, H. L., \& Milne, B. J. (2002). Males on the life-course-persistent and adolescence-limited antisocial pathways: follow-up at age 26 years. Development and Psychopathology, 14, 179-207.

32. Moule, Jr., R.K., Burt, C.H., Stewart, E.A., \& Simons, R.L. (2015). Developmental trajectories of individual's code of the street beliefs through emerging adulthood. Journal of Research in Crime \& Delinquency, forthcoming.

33. Moynihan, D. (1965). The Negro family: the case for national action. ("The Moynihan Report"). Washington, DC: U.S. Department of Labor.

34. Mulvey, E. P., Steinberg, L., Fagan, J., Cauffman, E., Piquero, A. R., Chassin, L., et al. (2004). Theory and research on desistance from antisocial activity among serious adolescent offenders. Youth Violence and Juvenile Justice, 2, 213-236.

35. Ousey, G. C., \& Kubrin, C. (2009). Exploring the connection between immigration and violent crime rates in US cities: 1980-2000. Social Problems, 56, 447-473.

36. Peterson, R. D., \& Hagan, J. (1984). Changing conceptions of race: towards an account of anomalous findings of sentencing research. American Sociological Review, 49, 56-70.

37. Poe-Yamagata, E., \& Jones, M. A. (2000). And justice for some differential treatment of minority youth in the justice system. Washington, DC: National Council on Crime and Delinquency.

38. Piquero, A. R. (2008). Disproportionate minority contact. The Future of Children, 18, 59-79.

39. Piquero, A. R., Farrington, D. P., \& Blumstein, A. (2003). The criminal career paradigm: background and recent developments. In M. Tonry (Ed.), Crime and justice: a review of research (Vol. 30, pp. 359-506). Chicago: University of Chicago Press.

40. Piquero, A. R., \& Brame, R. (2008). Assessing the race-/ethnicity-crime relationship in a sample of serious adolescent delinquents. Crime and Delinquency, 54, 390-422. 
41. Piquero, A. R., Moffitt, T. E., \& Lawton, B. (2005). Race differences in life-course-persistent offending. In H. Darnell \& K.-L. Kimberly (Eds.), Our children, their children: race/ethnicity and crime (pp. 202-244). Chicago: University of Chicago Press.

42. Piquero, A. R., Schubert, C. A., \& Brame, R. (2014). Comparing official and self-report records of offending across gender and race/ethnicity in a longitudinal study of serious youthful offenders. Journal of Research in Crime and Delinquency, 51, 525-555.

43. Piquero, A.R., Bersani, B.E., Loughran, T.A., \& Fagan, J. (2014). Longitudinal patterns of legal socialization in first generation immigrants, second generation immigrants, and native born serious youthful offenders. Crime \& Delinquency, forthcoming.

44. Sampson, R. J., \& Wilson, W. J. (1995). Toward a theory of race, crime, and urban inequality. In J. Hagan \& R. D. Peterson (Eds.), Crime and inequality. Stanford: Stanford University Press.

45. Sampson, R. J., \& Lauritsen, J. L. (1997). Racial and ethnic disparities in crime and criminal justice in the United States. In M. Tonry (Ed.), Ethnicity, crime, and integration: comparative and cross-national perspectives (crime and justice: a review of research (Vol. 21, pp. 311-374). Chicago: University of Chicago Press.

46. Savage, J. (2009). Understanding persistent offending: linking developmental psychology with research on the criminal career. In J. Savage (Ed.), The development of persistent criminality (pp. 3-33). New York: Oxford University Press.

47. Schubert, C. A., Mulvey, E. P., Steinberg, L., Cauffman, E., Losoya, S., Hecker, T., Chassin, L., et al. (2004). Operational lessons from the pathways to desistance project. Youth Violence and Juvenile Justice, 2, 237-255.

48. Sorenson, J., Hope, R., \& Stemen, D. (2003). Racial disproportionality in state prison admissions: can regional variation be explained by differential arrest rates? Journal of Criminal Justice, 31, 73-84.

49. Steffensmeier, D., Feldmeyer, B., Harris, C., \& Ulmer, J. T. (2011). Reassessing trends in Black violent crime, 1980-2008: sorting out the 'Hispanic Effect' in UCR arrests and NCVS offenders estimates. Criminology, 49, 197-251.

50. Stewart, E. A., \& Simons, R. L. (2010). Race, code of the street, and violent delinquency: a multilevel investigation of neighborhood street culture and individual norms of violence. Criminology, 48, 569-605.

51. Sweeten, G., Piquero, A. R., \& Steinberg, L. (2013). Age and the explanation of crime revisited. Journal of Youth and Adolescence, 42, 921-938.

52. Sykes, B. (2014). Documentation and methods for incarceration rates in the United States, 1972-2010. Appendix B (Data Sources). In T. Jeremy \& W. Bruce (Eds.), The growth of incarceration in the United States: exploring causes and consequences. Washington, DC: National Academies Press, for the National Academy of Sciences.

53. Sykes, B., Gioviano, J., \& Piquero, A.R. (2014). Mentoring marginality: the role of informal mentors in the lives of socially disadvantaged youth. Race and Justice: An International Journal, forthcoming.

54. Thornberry, T. P., \& Krohn, M. D. (2003). Comparison of self-report and official data for measuring crime. In J. V. Pepper \& C. V. Petrie (Eds.), Measurement problems in criminal justice research: workshop summary (pp. 43-94). Washington, DC: National Academy Press.

55. Tracy, P. E., (1987). Race and class differences in official and self-reported delinquency. In M. E. Wolfgang, T. P. Thornberry, \& R. M. Figlio (Eds.), From boy to man, from delinquency to crime (pp. 87-121). Chicago: University of Chicago Press.

56. Truman, J., Langton, L., \& Planty, M. (2013). Criminal victimization, 2012. Washington, DC: U.S. Department of Justice, Bureau of Justice Statistics.

57. Tsang, S., Cauffman, E., \& Piquero, A. R. (2014). An examination of the Psychopathy Checklist: Youth Version among male adolescent offenders: an item response theory analysis. Psychological Assessment, 26, 1333-1346.

58. Vélez, M. B. (2009). Contextualizing the immigration and crime effect: an analysis of Chicago neighborhoods. Homicide Studies, 13, 325-335.

59. Weitzer, R. (1996). Racial discrimination in the criminal justice system: findings and problems in the literature. Journal of Criminal Justice, 24, 309-322. 